Article

\title{
Integration of Improvement Strategies and Industry 4.0 Technologies in a Dynamic Evaluation Model for Target-Oriented Optimization
}

\author{
Sergio Gallego-García ${ }^{1, *}$, , Marcel Groten ${ }^{2}$ and Johannes Halstrick ${ }^{3}$ \\ 1 Industrial Engineering Technologies of the International School of Doctorate, \\ National Distance Education University (UNED), 28040 Madrid, Spain \\ 2 Project Portfolio and Production Management, Bayer AG, Pharmaceuticals, 51373 Leverkusen, Germany; \\ marcel.groten@hotmail.de \\ 3 Roland Berger $\mathrm{GmbH}$, 60306 Frankfurt am Main, Germany; johalstrick@gmail.com \\ * Correspondence: sgallego118@alumno.uned.es; Tel.: +34-682-880-591
}

check for updates

Citation: Gallego-García, S.; Groten, M.; Halstrick, J. Integration of Improvement Strategies and Industry 4.0 Technologies in a Dynamic Evaluation Model for TargetOriented Optimization. Appl. Sci. 2022, 12, 1530. https://doi.org/ 10.3390/app12031530

Academic Editors: Piera Centobelli, Richard (Chunhui) Yang and Emanuele Carpanzano

Received: 10 November 2021

Accepted: 18 January 2022

Published: 31 January 2022

Publisher's Note: MDPI stays neutral with regard to jurisdictional claims in published maps and institutional affiliations.

Copyright: (C) 2022 by the authors. Licensee MDPI, Basel, Switzerland. This article is an open access article distributed under the terms and conditions of the Creative Commons Attribution (CC BY) license (https:// creativecommons.org/licenses/by/ $4.0 /)$.
Featured Application: Facilitate the optimization of relevant KPIs to increase the long-term sustainability of manufacturing organizations thanks to a novel model for the integration of improvement strategies and Industry 4.0 related technologies, and for an optimized sequence model for Industry 4.0 technologies, the GUVEI-Model, as well as for the dynamic evaluation for defining optimization alternatives aligned with organizational targets.

\begin{abstract}
Many improvement techniques, methods, and technologies have been the driver of the development of supply chain systems. However, many managers and companies are focused only on new technologies without considering a comprehensive evaluation, and therefore lacking a real need and purpose. As a result, practitioners are often confused with regard of how to integrate improvement strategies and new technologies, as well as how to evaluate their convenience. Thus, this research aims to develop a model for the assessment for each manufacturing capability. This assessment aims to enable a continuous business transformation aligned with organizational goals; thus, a dynamic maturity assessment is chosen. Based on this, the study seeks to provide an integration model for relevant improvement strategies and new technologies that can be applied to any organization. As a result, the paper develops a sequence model, the GUVEI-Model, for the application of Industry 4.0 related technologies for continuous improvement in five different clusters. Furthermore, the research develops an evaluation scheme of optimization alternatives. Based on this conceptual development, a simulation model is built for specific use cases, such as additive manufacturing or virtual reality. The results show how the use cases along the GUVEI-Model application improve relevant indicators significantly, with the first two steps, obtaining and using data, acting as enablers of the three subsequent optimization steps that allow the virtualization, expansion, and improvement of capabilities and a higher impact on the target indicators than the first two steps. Finally, a discussion is presented about the utility of digital twin models for dynamic maturity level assessment and for simulating project improvement impacts before, during, and after their implementation.
\end{abstract}

Keywords: improvement strategies; Industry 4.0; project evaluation; optimization; dynamic maturity assessment model; organizational capabilities; business transformation; strategic management; simulation; system dynamics

\section{Introduction}

Industrial productivity growth has always been influenced by the increasing capabilities of technologies. Now, the fourth industrial revolution is emerging, although it has not yet been fully implemented [1]. Some name it the fourth industrial revolution; 
others, the third industrial revolution; and some people refer to it as the second machine age [2]. The term I4.0 refers to a technology-oriented production paradigm that connects cyber and physical environments based on automation. The integration of I4.0 technologies is expected to imply significant improvements [3]. Moreover, this new industrial stage demands a socio-technical evolution of the human role in production systems, in which all working activities of the value chain will be performed with smart approaches and grounded in information and communication technologies (ICTs) [4].

Nowadays, global competition is becoming more and more intense and new technological advancements are being developed constantly. Thus, towards meeting market requirements effectively, organizations must improve their overall operational performance continuously. In order to achieve this goal, a wide range of methodologies are available, including, among others, lean manufacturing (LM), lean Six Sigma (LSS), quick response manufacturing (QRM) and theory of constraints (TOC), which appear to be amongst the most popular methods across the academic literature [5]. In this context, integrating both the spheres of lean manufacturing, and other improvement strategies and Industry 4.0 is an important research field to be extensively explored [6].

Several studies have studied the compatibility and integration of Industry 4.0 and lean manufacturing within an organization [7]. Contrary to popular belief, lean production does not exclude automation. In the 1960s, Ono claimed that process should be automatized and supervised by employees, the principle autonomation. This corresponds to Industry 4.0, by which humans—supported by innovative technology—take the same role [8].

In this context, one needs to consider that current manufacturing has not achieved Industry 4.0 level, although many researchers and companies are working on this topic [9]. However, there is still a long way to go to improve manufacturing up to the required level [10]. The introduction of Industry 4.0 technologies will enable manufacturers to cope with increasing product variety and global competition. However, adapting to it rapidly and frequently is a challenging task [11]. Furthermore, although IT is already at the heart of manufacturing, and technological innovations, such as sensors, actuators, and computerized automation, have been used by manufacturing companies for decades, there has been limited benefits provided by them. In other words, the full potential of these technologies has not been realized [12]. As a result, Industry 4.0 is increasingly being explored by academics, researchers, practitioners, and other relevant stakeholders. As a result, there are great expectations in both the research and business communities that such technologies will permeate into manufacturing supply chains and the service sector [13].

The concept of Industry 4.0 remains strongly linked to technologies and frameworks researched and analyzed in the last decades. In particular, Industry 4.0 can be seen as a smart recombination of existing technologies and some new technologies and their application to the manufacturing environment [14], with some authors claiming that it is based on a rebirth of Computer Integrated Manufacturing [8,14].

Previous academic research and white papers have summarized the main technologies related to Industry 4.0, however, these do not address how the companies providing or implementing manufacturing technologies are adapting themselves to implement and offer Industry 4.0 solutions [15]. The Industry 4.0 concept has a very complex technology architecture in terms of its manufacturing systems. Therefore, the effective implementation of Industry 4.0 technologies is still a subject of research [4]. In this situation, maturity models for Industry 4.0 aim to determine which capabilities a manufacturing organization needs to acquire in order to successfully introduce Industry 4.0 in a standardized way [16]. Some prior works have proposed maturity models for the implementation of these technologies, while other works have studied the impact of these technologies on industrial performance. However, there is a lack of studies providing empirical evidence about the way these technologies are adopted in manufacturing companies [4]. In this context, several maturity models have emerged to provide recommendation for the future implementation of Industry 4.0 related technologies, techniques and methods. Thus, an organization can determine improvement potentials based on the maturity level results [17]. In this line, 
Lu and Weng (2018) propose a smart manufacturing key technology architecture [18]. Zeller et al. (2018) provide a development path based on computerization, connectivity, digital visibility, transparency, and predictive capabilities enabling the simulation of different future scenarios [19]. Moreover, Lee et al. (2014) propose a model with a 5-level CPS structure, providing a step-by-step guideline for developing and deploying a CPS for manufacturing application [20].

Therefore, many companies face the challenge of assessing the diversity of developments and concepts summarized under the term Industry 4.0 and developing their own corporate strategies [16]. The integration of the Industry 4.0 concept into a company's manufacturing line encompasses a wide range of technologies, from specific production improvements (such as collaborative robots) to applications that connect different companies of the supply chain (like cloud computing) [15]. Since Industry 4.0 is still in the initial stages of its development, it is essential to clearly define the structure and methodology of implementation guidelines for Industry 4.0 specifically. Therefore, there is a fundamental need to assist organizations in their business transformation process to the Industry 4.0 environment and to guide them for improving their capabilities [16]. From a socio-technical perspective, it is acknowledged that the adoption of the emerging technologies of the Industry 4.0 need at least three complementary socio-technical dimensions: organization of work, human factors and external environment [21].

For implementing Industry 4.0 in a standardized way, one of the biggest challenges is how to turn data into valuable information that will facilitate decision making and how Industry 4.0 can be operationalized in manufacturing. With this goal, systems theory appears as a formal way to analyze this challenge as it is, mainly, focused on the interaction between the main components of the system, and considers organizations as whole and integrative entities [12]. Moreover, there is a need for research in terms of the analysis of the return on investment (ROI) of advanced technological innovations of Industry 4.0 in organizations [12]. The definition of a proper strategy to implement I4.0 technologies, and the opportunities in business models are two major trends that need to be further explored in new studies [15]. Furthermore, there is also a need to study the effect of Industry 4.0 related technologies on industrial performance; although there are studies at the industrylevel, there is still a need to study how these technologies impact on industrial performance at the firm level [4].

Based on the literature, the main research gaps can be summarized as follows:

1. Integration models of improvement strategies and Industry 4.0 technologies [7,16];

2. Models and sequences for the successful implementation of Industry 4.0 technologies within manufacturing organizations $[4,15,16]$;

3. Models for maturity assessment to standardize the introduction of Industry 4.0 technologies including the impact assessment after their implementation $[4,16]$;

4. Models for the evaluation of optimization alternatives under Industry 4.0 environments $[4,12,16]$;

5. Quantification models for specific use case evaluation under Industry 4.0 environments $[4,12]$.

Based on the above-mentioned research gaps, as well as taking into account that some of these gaps have been analyzed for decades [12], the research that is to be performed acquires greater relevance and significance. Thus, the aim of the study is to tackle these challenges with a unique approach ranging from the generic perspective of the strategic integration of various methodological and technological optimizations to specific use cases through a model for continuous business transformation based on the current functional maturity level of the manufacturing organization.

Currently due to the advent of the Industry 4.0 concept and digitizing initiatives, many managers and companies act as "technology fans", forgetting any other strategies and methods and focusing only on developing and implementing new technologies. As a result, they have initiated and implemented Industry 4.0 related technological projects without considering a " 360 " evaluation, therefore lacking a real need and purpose and 
not contributing more than the implementation of a "interesting technological gadget or system" and incurring a waste of different company resources, such as time, money, etc. Thus, the research aims to develop a model for the assessment attending to real organizational needs and based on the main areas and factors for each manufacturing function, as well as on market that enables continuous business transformation that are aligned with the required current and future manufacturing organizational capabilities. Furthermore, the conceptual model provides also a description of production areas and factors to be assessed to determine the current maturity level of organizational capabilities.

Even with a business transformation model and areas and factors to identify capability gaps, practitioners are often confused with regard of how to integrate improvement strategies and new technologies, as well as how to evaluate their convenience. This is why the present paper seeks to provide an integration model for relevant improvement strategies and new Industry 4.0 technologies that can be applied to any organization. Moreover, the paper develops a sequence for continuous improvement in five different clusters. Both the integration model and the five clusters of Industry 4.0 technologies represent novel approaches that serve as a guide for developing optimization roadmaps. Furthermore, the research develops an evaluation scheme for new initiatives within manufacturing organizations. In addition, a simulation model is built for the application of the conceptual model for specific use cases, such as additive manufacturing or virtual reality, providing a methodology for the assessment of Industry 4.0 related technologies in a quantitative way. Furthermore, knowing the impacts of Industry 4.0 technologies implementation on target indicators helps to provide fundamental information to decide on future projects to include in strategic company roadmaps. Finally, a discussion about digital twin future applications for project evaluations with a dynamic maturity assessment is presented.

\section{Methodology, Fundamentals, and Materials}

\subsection{Methodology}

In this paper, the methodological approach is as follows:

1. Literature research on:

(a) Organizational areas of manufacturing companies and current challenges in organizational assessments based on maturity level models.

(b) Identification of optimization alternatives in Industry 4.0 environments.

2. Development of the conceptual model for the continuous improvement of manufacturing organizations to achieve their organizational goals.

3. Description of production areas and factors for the design, monitoring, and assessment of manufacturing organizations.

4. Derive how the optimization alternatives, which in this research are relevant improvement strategies and new technologies within Industry 4.0 environments, can be integrated into a model with different recommended sequential steps. Additionally, determine how the different Industry 4.0 related technologies can be implemented for the optimization of the production system.

5. Development of an evaluation scheme for new optimization alternatives which can serve as a framework for optimal decision-making when selecting appropriate concepts, techniques and steps for new improvement project initiatives.

6. Design of simulation models for modelling and assessing the different steps of the sequence model for Industry 4.0 related technologies.

7. Discussion of how to apply the conceptual and simulation models for developing digital twin models for dynamic maturity assessments providing insights on the impacts of Industry 4.0 related technologies implementation projects.

8. Critical reflection of the research performed, and outlook of potential future research based on the paper. 
Cooperation between research partners and the chosen methodological approach was achieved through a combination of a literature review, generic conceptual development, and simulation techniques in specific use cases.

\subsection{Organizational Areas and Maturity Models}

Organizational functions, as described from Porter, can be divided into primary and support functions, which are activities that describe the value chain of an organization that are related to its competitive strength. Primary activities are directly concerned with the creation or delivery of a product or service. They can be grouped into five main areas: inbound logistics, operations, outbound logistics, marketing and sales, and service. Primary activities are linked to support activities which help to improve their effectiveness or efficiency. There are four main support activities: procurement, technology development, human resource management, and infrastructure [22].

In the organization context, the notion of maturity is used to define, assess and form a guideline and a basis for evaluating the progress in business (i.e., the maturity of process or a technology). As the degree of maturity becomes higher, better progress is achieved in different aspects that contribute to the maturation of the entity [16]. To measure the degree of progress and advancement, maturity models were developed. Usually applied to new technologies, their goal is to provide insight into continuous process improvement and status quo analysis. As a whole, the maturity model describes an anticipated, desired or typical development trajectory [17]. There are various well-accepted generic software process capability/maturity models (SPCMMs), as well as models based on the ISO/IEC 15504 in providing a common baseline for capability assessment, and to report the assessment outcome by employing a common measurement scale [16]. Schuh et al. [23] have developed a maturity model of organizational structure that can be used to manage the digital transformation of companies in the context of industry 4.0. Having highly skilled workforces with a high degree of individual responsibility in a dynamic environment, collaborating within the entire value network, is of great importance [24]. A common procedure to methodically support the implementation of Industry 4.0 has not yet been established throughout the industry and, hence, maturity models are not notably common as well. Moreover, procedure models are generally applied, which mostly lack a specific assessment or measurement, as well as a goal-oriented model [17]. Maturity models or frameworks aim to assist organizations by providing comprehensive guidance for roadmap definition [16]. Industry 4.0 investments should be carried out using an integrative approach that usually involves a roadmap, which is an overall plan for the deployment of new technologies, containing organizational change, that explains the main phases that needs to be taken. This digital transformation roadmap is unique for every manufacturing company and requires the involvement of all organizational levels and decision makers [25].

\subsection{Optimization Alternatives: Improvement Strategies and New Technologies}

Nowadays, there is significant pressure on organizations to improve customer satisfaction and quality levels, and at the same time to decrease ineffectiveness and reduce the number of errors. Organizations need to gain and retain customers, as they are the key elements that drive the economy. There are many different conceptions, methods and tools that may be used to maintain a good quality level and help in the continuous development of a company [26]. For this purpose, and as a result of more than 60 years of the study of production systems, Toyota has developed a range of methodologies and tools that have been tested around the world by companies of all sizes and sectors, obtaining huge improvements in all of their processes and equally significant reductions in production costs [27]. From this development, other strategies have added conceptual and practical frameworks in order to achieve strategic improvement. Some of the most relevant strategies are presented below:

- Lean manufacturing (LM): Lean manufacturing arose from the Toyota Production System and is described as manufacturing without waste [28]. 
- Six Sigma (SS): After the inception of TQM in the early 1980s, Six Sigma emerged as an element of TQM that could be seen as the current state of evolution in quality management. Six Sigma is a strategy that helps to identify and eliminate the defects which lead to customer dissatisfaction in tire industries [29].

- Theory of constraints (TOC): Goldratt (1990) declares that "any system in reality must have at least one constraint". In the case of chains, the strength of the whole chain equals the strength of the weakest link. Similarly, in the case of organizations' performance, the final throughput of a company is limited by the resource with the lowest capacity [5].

- $\quad$ Quick response manufacturing (QRM): Based on time-based competition (TBC), $\mathrm{QRM}$ is a companywide strategy in which the main focus is to reduce the lead time [28].

- $\quad$ Agile manufacturing (AM): Agile manufacturing is a responsive manufacturing strategy with the goal to survive in continuously and unpredictably changing environments as it focuses on fast response throughout the supply chain to mitigate the effects of variability [30].

Groten and Gallego-García (2021) developed a systematic improvement model for the integration of relevant improvement strategies for the design and optimization of manufacturing organizations [31]. This model considers the most relevant strategies described before and it is used as basic framework to study the integration of improvement strategies and the Industry 4.0 related technologies studied in this research paper. Moreover, a survey of 200 manufacturing companies demonstrates how lean strategy is also pursued together with the implementing of Industry 4.0 solutions, although this study also showed how managers are concerned with making new technologies compatible with the dynamism of lean environments [32].

Industry 4.0 consists of several vaguely defined and partly overlapping technologies [33]. Both lean production and Industry 4.0 favor decentralized structures over large, complex machines and both aim for small modules with a low level of complexity [8]. As described in the previous chapter, the integration of Industry 4.0 solutions matches lean philosophy and the mentioned examples proved feasibility. Industry 4.0 can be integrated in lean production and, beyond that, can improve lean production with increased integration of ICT. Applying Industry 4.0 to established lean production could lower the risks of integration due to existing advice for organizational integration. Additionally, production processes in lean production are, in comparison to other kinds of organizations, more standardized, more transparent and reduced to essential work. As a result, they are less complex and support the installation of Industry 4.0 solutions [8]. Companies indicate standardization as a highly important precondition. Standardized systems, platforms, processes, and interfaces comprise the crucial infrastructure for easier implementation of Industry 4.0 [34]. Industry 4.0 targets the implementation of interconnecting, smart, and self-controlled structures of processes and systems [16].

For the successful implementation of Industry 4.0 transformation, three core and nine fundamental technologies are required to be part of the entire system [35]. For these technologies, the capabilities that they provide are analyzed for each of them: adaptive robotics, CPS, additive manufacturing, cloud technologies, virtualization technologies (virtual reality (VR) and augmented reality (AR)), simulation, data analytics and artificial intelligence (AI), communication and networking, real time location systems (RTLS) and radio-frequency identification (RFID), cyber-security, sensors and actuators, and mobile technologies [36]. For the research performed, this model, with twelve Industry 4.0 technologies and their related capabilities [36], is selected as basic framework for the integration in the conceptual model. In this context, recent findings of the literature have shown that the industry varies in the benefits expected by those technologies for industrial performance which indicates that companies should think systemically about the implementation of such technologies in order to achieve a higher maturity level of Industry 4.0 [4]. 


\subsection{Materials}

The following sources, methods and tools were used to perform the research:

- Literature review: It is based on the search of articles, books, conference papers, etc., for the following keywords: "Capability Maturity Model"; "Industry 4.0 Maturity Model"; "Dynamic Maturity Model Assessment"; "Improvement Strategies"; "Industry 4.0 technologies"; "Integration of Lean and Industry 4.0"; "Integration of improvement strategies and Industry 4.0"; "Implementation sequence of Industry 4.0 technologies"; and "Evaluation Scheme for Industry 4.0 technologies".

- System Dynamics: System dynamics is a computer-guided approach for studying, managing and solving complex feedback problems with a focus on policy analysis and design [37].

- $\quad$ Simulation and Vensim Software: Simulation is the only practical way to test models because our mental models are dynamically deficient, omitting feedback, time delays, accumulations and nonlinearities [38]. For all of these reasons, simulation is used to reproduce the conceptual model and to validate the initial hypotheses. In the market, there are different software packages that enable system dynamics modeling, such as: AnyLogic, DYNAMO, iTHINK, POWERSIM, STELLA and VENSIM [39]. From these, VENSIM simulation software was selected for the research.

\section{Conceptual Model Development}

\subsection{Model for Continuous Business Transformation Aligned with Current and Future} Manufacturing Organisational Goals

A company needs to change in a continuous way in order to be viable over time. For that purpose, the model in Figure 1 is developed. Thus, the model considers the organization-related environment dynamics; the current capability maturity level of the organization, including an evaluation of processes; the organizational structure, including staff qualification and related indicators, systems, available methods, organizational setup, and systems, as well as the expected company dynamics; the existing optimization alternatives; and a target system of indicators for the evaluation of new initiatives that incur investments, costs, time, space, etc.

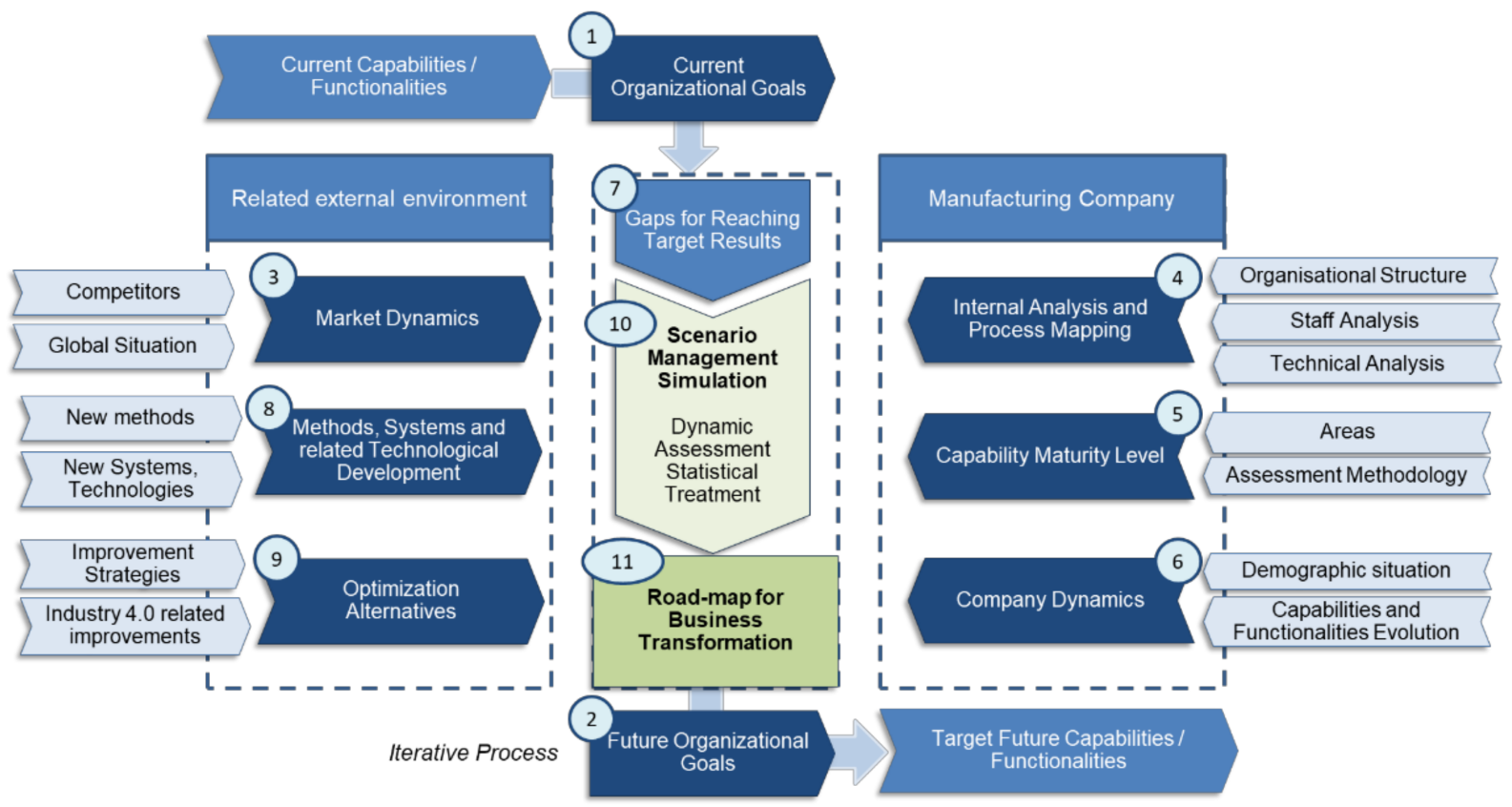

Figure 1. Model for continuous business transformation aligned with current and future manufacturing organizational goals (own elaboration). 
The model is designed based on the current given capabilities and organizational goals of a manufacturing company. On this basis and with the goal of securing long-term viability, a company needs to define future organizational goals with related future capabilities to face expected market dynamics. However, for developing these future capabilities, a detailed analysis of the organizational structure and related staff and functions, as well as an analysis and process mapping of technical and management processes must be performed. Based on this analysis, the capability level for each area can be determined by applying a defined assessment methodology. Furthermore, to complete the internal analysis of a manufacturing company the historical dynamics, as well as the human factor evolution needs to be considered. In this context, gaps to reach the target capabilities can be at first defined. Moreover, existing and new methods, systems, and technologies need to be analyzed to developed optimization alternatives with improvement strategies and Industry 4.0 technologies. As a result, the different alternatives and future external environment dynamics can be simulated, providing a dynamics assessment of future scenarios to determine when and which improvement project initiatives are to be included in the business transformation roadmap.

\subsection{Production Areas and Factors for Maturity Level Evaluation}

After having defined the generic conceptual framework, the areas for identifying the gaps and for improving related capabilities needs to be defined. For that reason, the production activities are grouped in eight different modules as can be seen in Figure 2 . First the strategic level is to be defined, later the required technical process changes can be derived, as well as the related production factors for performing the ultimate processes. Afterwards, the operative and tactical management levels can be determined, followed by developing a vertical integration within the plant or the production network. Finally, the horizontal integration among supply chain partners is to be assessed, along with the impacts of the action of the production system or network in the related environment:

\section{Module 7: Horizontal integration}

Module 1: Strategic management
Module 5: Tactical management
Module 4: Operative
Management
Module 2: Technical
Processes
Module 3: Production factors
the related environment

Figure 2. Production areas for manufacturing assessment (own elaboration). 
Later, for a more detailed definition of the capabilities of the manufacturing organization, the tasks and factors associated with each module are described in Figure 3. This shows how an organization can be broken down into eight areas, each of them with relevant factors that have a specific state, on-going projects and activities, and future optimization plans. Therefore, it is key to develop this framework for any manufacturing organization, as it provides the basic understanding of all manufacturing functions, areas, and factors. Based on it, a maturity assessment can be performed and the results regarding which areas are in need for improvement in order to achieve organizational targets can be derived. The areas of the model would be represented in any manufacturing organization while the manufacturing factors depend on the sector, on the technical and management processes, on the organizational state, and on the supply chain partners and other stakeholders:

\begin{tabular}{|c|c|c|c|c|}
\hline \multirow{2}{*}{$\begin{array}{l}\text { Module } 7 \text { : Horizontal } \\
\text { integration }\end{array}$} & Inbound Logistics & Outbound Logistics & SCM-Systems & Contracts \\
\hline & Procurement Logistics & Distribution Logistics & Partnerships & $\ldots$ \\
\hline Suppli & & OEM & & \\
\hline
\end{tabular}

\begin{tabular}{|l|c|c|c|c|}
\hline $\begin{array}{l}\text { Module 1: Strategic } \\
\text { management }\end{array}$ & Business Model \\
\hline $\begin{array}{l}\text { Module 5: Tactical } \\
\text { management }\end{array}$ & Product Program & Production structure \\
\hline $\begin{array}{l}\text { Module 4: Operative } \\
\text { Management }\end{array}$ & Batch size & Detail Scheduling \\
\hline
\end{tabular}
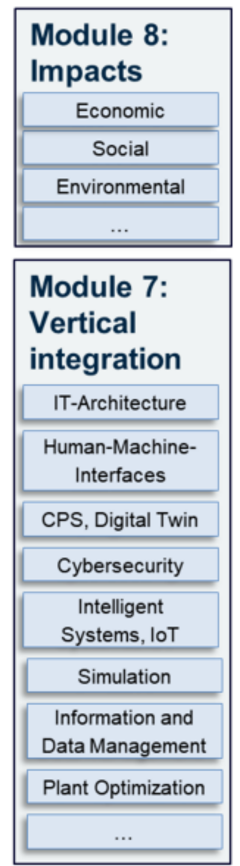

Figure 3. Manufacturing functions assessment model based on areas and factors (own elaboration).

\subsection{Integration of Improvement Strategies and Industry 4.0 Technologies}

After having described the generic process and the areas, tasks and factors where improvements could be required to enhance production capabilities up to the required level, it is the moment to identify first the improvement options, as presented in Section 2.3, as well as to determine how the options can work together in a logical and efficient way to develop a generic model. To integrate the Industry 4.0 related technologies with relevant improvement strategies, a matrix was developed to syndicate when it is recommended to initiate Industry 4.0 projects in relation to the lean optimization steps. As a result, Figure 4 shows that it is recommended to perform the improvement strategy projects before, after or in parallel with Industry 4.0 projects related to new technologies. The technologies used for integration are the fundamental and core Industry 4.0 technologies extracted from the literature [34]. In addition, the integration matrix is built based on the main characteristics of the technologies and of the lean steps.

The matrix should be read as follows in order to understand its logic. How to read the matrix: "It is recommended to perform T1 (Sensors and actuators) projects before analyzing the current state of the production system" as T1 would enable more data to be gathered, and therefore, more information would be available, increasing, as a consequence, the accuracy of the current state of analysis. The following recommendations can be read in Figure 4: before (B), in parallel (P), after (A), before and in parallel (BP), before and after (BA), in parallel and after (PA), before, in parallel and after (BPA): 


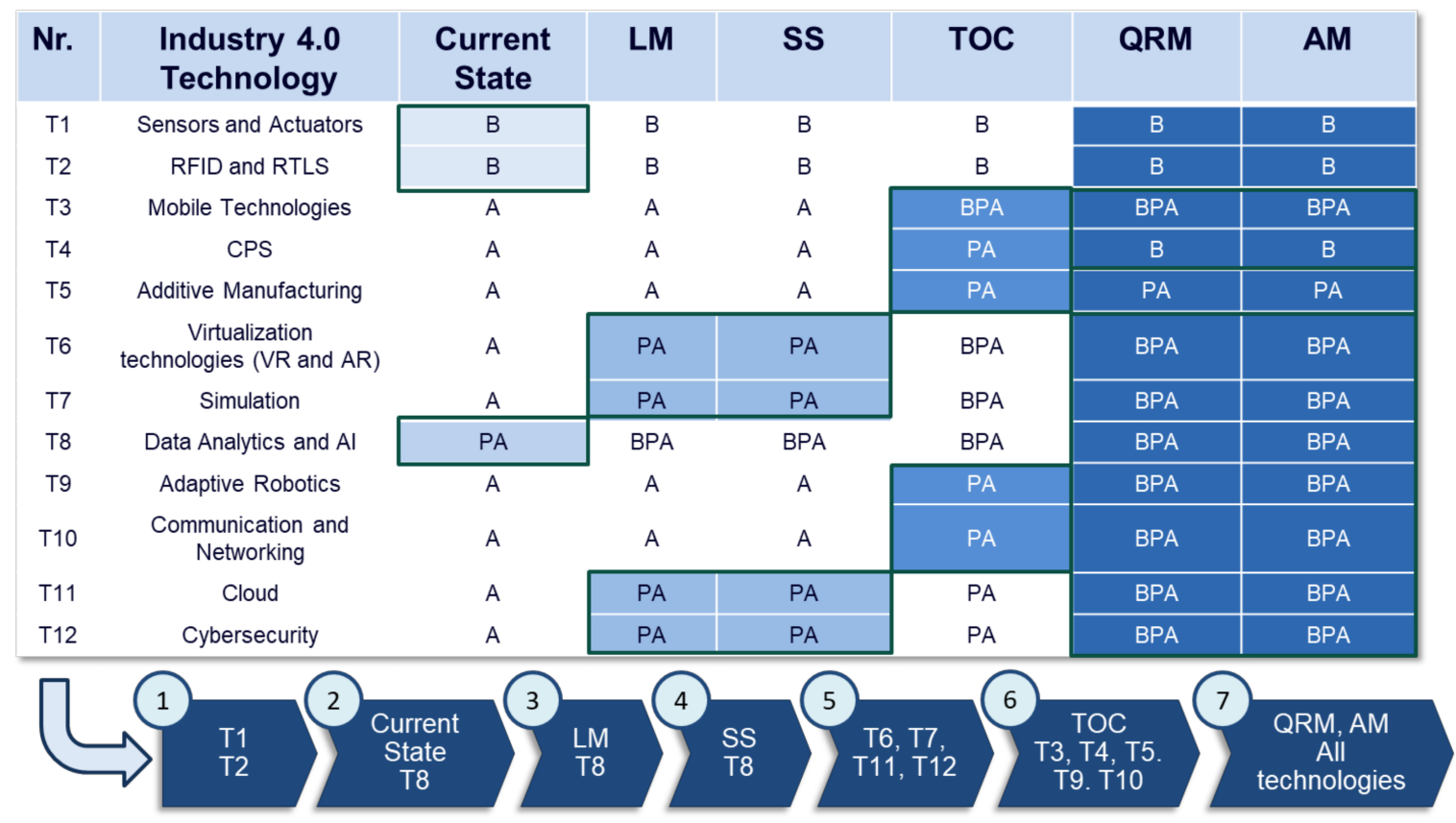

Figure 4. Integration of improvement strategies and Industry 4.0 technologies (own elaboration).

Based on Figure 4 and the classification of recommendations (B, PA, BP, BPA, PA, A) included in it, clusters can be built. As a result of this clustering, Figure 5 allows us to describe the integration of improvement strategies and Industry 4.0 related technologies in five steps called the "GUVEI-Model", which stands for the get, use, virtual, expand, improve (GUVEI) model.

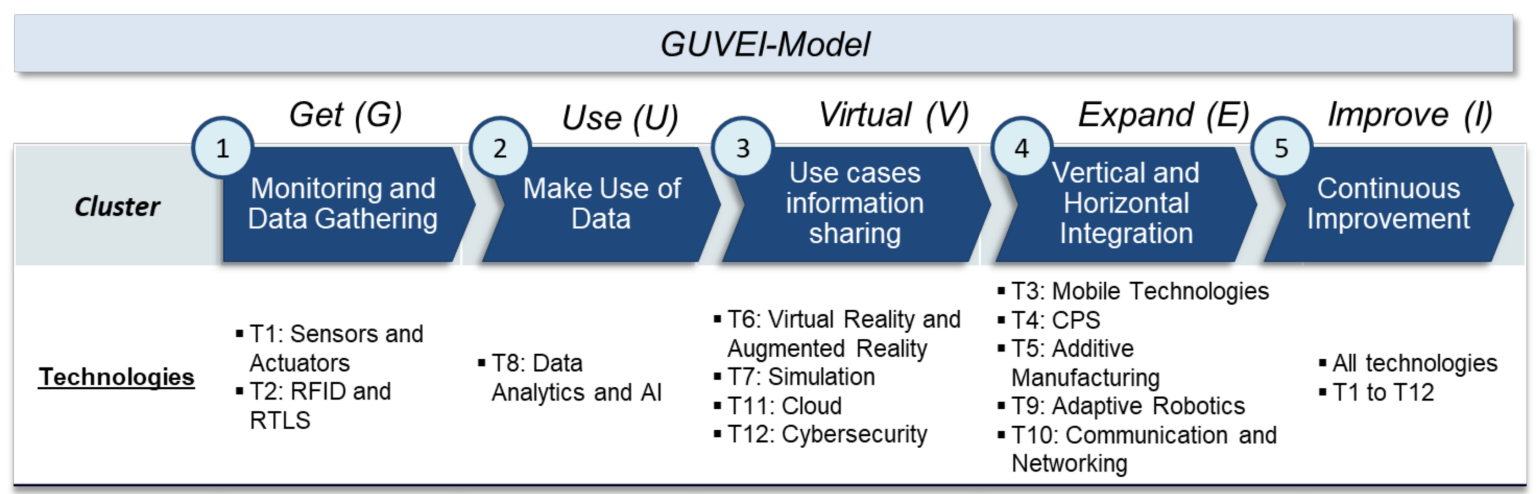

Figure 5. GUVEI-Model for Industry 4.0 technologies implementation (own elaboration).

1. Cluster 1-Monitoring and data gathering phase: it consists of sensors and actuators (T1) as well as RFID and RTLS (T2) for the system monitoring enabling, and also works to collect data about products, equipment, staff, tools, etc. This phase is recommended to be implemented before starting the lean optimization process. This cluster makes it possible to have less product, equipment, staff coordination, data quality failures, and less production lead time as it would be easy to find and know the status of any element, as well as less reaction time for maintenance activities as breakdowns would be known in real time.

2. Cluster 2-Make use of data phase: from the data collected, the second phase deals with the transformation of this data into usable information in order to support decision-making activities at the strategic, tactical and operative levels. For this purpose, phase 1 serves as the basis and T8, data analytics and artificial intelligence, serve as means. This step is recommended to be applied as soon as data are available 
and therefore it can be tackled in parallel or after the analysis of the current state or in any moment of the lean optimization steps, as soon as reliable data is available.

3. Cluster 3-Applying and sharing information knowledge for specific purposes phase: information from the previous phase can be shared with different locations at any time with cloud technology (T11), with cybersecurity (T12) and also applied for specific purposes. Virtual reality (VR, T6) can be, for example, applied for training and improving manual assembly activities; augmented reality (AR, T6) can be applied for improving maintenance activities on-site; and simulations (T7) can be applied for improving decision-making for various what-if scenarios of the production system. This step is recommended to be applied after the current state has been analyzed and all available data have been gathered. As a result, it could be initiated in parallel or after the lean manufacturing and Six Sigma optimization steps.

4. Cluster 4-Development of end-to-end vertical and horizontal integration phase: with data availability, information based on this data, and already specific applications, a global solution with interactions of suppliers, producers and distributors, as well as with the real-time interaction of all different agents, persons, products, equipment, etc., interacting in the production system can be implemented. For this purpose, cyber-physical-systems (T4) can be developed by building digital twin models of the production system using communication and networking technologies (T10) that can provide real-time information anywhere with mobile devices (T3) and are applied for introducing self-adaptive/optimized robots (T9). This step is recommended to be applied after the lean manufacturing and Six Sigma optimization steps and in parallel or after the application of the TOC.

5. Cluster 5-Make it fast, effective, and with efficiency: it refers to the continuous optimization of the technologies already implemented in the previous clusters, as well as to the improvement of lead times, effectiveness and efficiency with the use of additive manufacturing (T5). This step is recommended to be applied in parallel or after the introduction of QRM and AM.

\subsection{Evaluation Scheme for Optimization Alternatives}

When an organization has a capability need, different potential improvement options are available. All of them have different effects on the satisfaction level of the capability need. However, the resources needed as well as implementation time and risk need to be considered. In addition, an economic assessment and other impacts are to be considered, as shown in Figure 6:

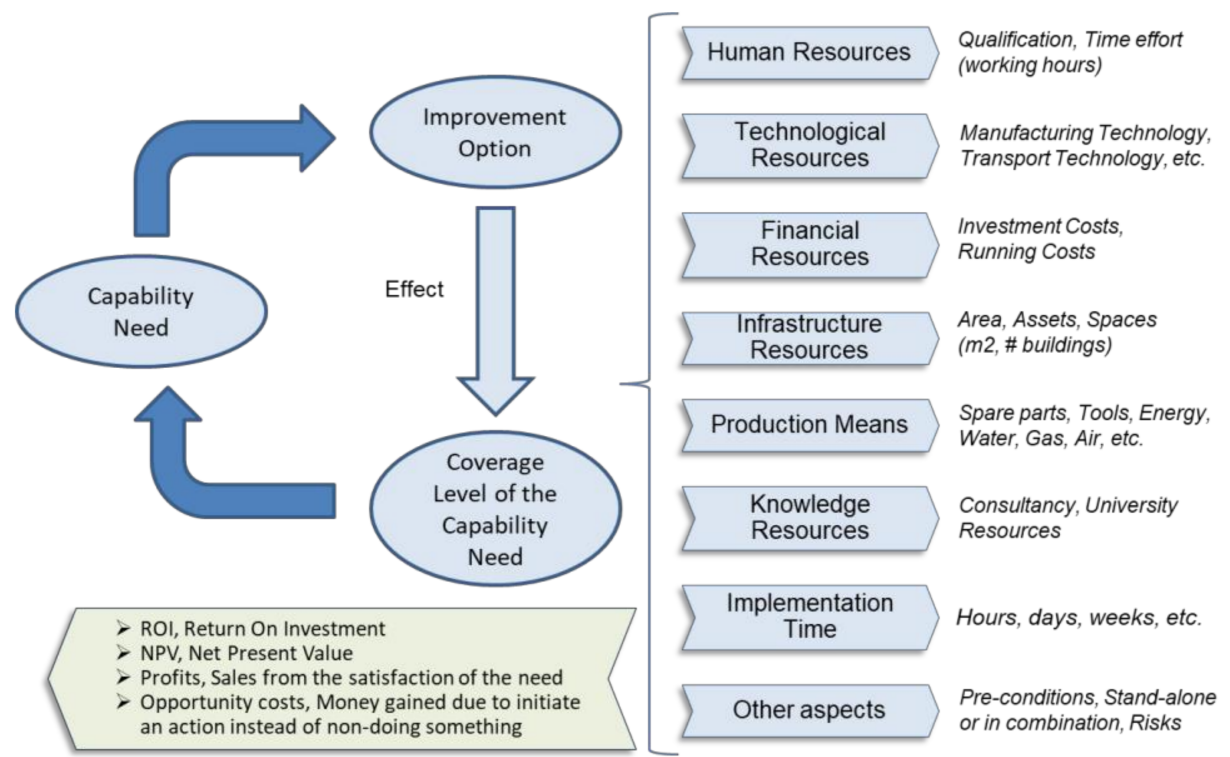

Figure 6. Scheme for evaluation of optimization alternatives (own elaboration). 


\section{Simulation of Use Cases}

Firstly, the goal of the use cases, the scope and the methodology must be defined. The goal of the simulation study is to design a generic simulation model for the quantification of the evaluation scheme parameters along the GUVEI-Model sequence. For each specific use case, a new simulation model is generated in which the simulation logic is adapted according to the different improvements applied. The scope of the study is:

- Generic simulation model serving as basis for develop specific simulation models. It provides the required complexity level as well as implements the criteria for enabling later comparisons.

- Specific simulation models for a selection of technologies from the ones exposed in Section 3. The scope of these models does not include all of the potentials within the technology cluster, but a specific use case for the technology that will be specified in Section 4.2, where the logic and implications of the models are also to be explained.

The hypotheses of the case studies are:

- Improvement of some indicators with each Industry 4.0 technology use case.

- Some Industry 4.0 case studies may need to assume previous lean activities to be coherent. For the methodological framework the following steps will be followed:

1. Definition of the objective, scope, hypothesis and methodology, including a general description of target simulation models and scenarios;

2. Definition of the production system: flow and characteristics;

3. Definition of quantitative parameters, key performance indicators (KPIs) to obtain results and compare models;

4. Determination of the interrelationships among variables within the model;

5. Description of the main assumptions for the simplification of the complexity of the model;

6. Creation of the simulation models based on various Industry 4.0 case studies;

7. Validation of the behavior of the simulation models;

8. Determination of scenarios;

9. Simulation and extraction of results;

10. Evaluation of the results and derivation of conclusions.

\subsection{Design of the Generic Use Case}

This sub-chapter includes the generic description and specifications of the simulation model applied for all use cases. The general framework described in it applies for all specific simulation models.

\subsubsection{Structure of the Simulation Use Cases: Production System Flow and Characteristics}

Firstly, this sub-chapter describes the general structure of the simulation models that are applied for all simulation models within the simulation use cases. The structure is generated to provide the necessary production system flow and characteristics in order to answer the research question. Thus, as can be seen in Figure 7, the structure considers a production system within a supply chain of suppliers-production system-distributorsretailers/customers serving as a generic framework applicable for any sector. Moreover, the production system consists of technical processes, that is, the execution of the transportation, warehousing and production of finished products, as well as of management processes, systems and organizational structures, from the operational to strategic levels.

As a summary, all models have a set of suppliers, one raw materials warehouse, three production processes, one finished products warehouse, a set of distributors and three retailers serving end-customers each with a certain demand. All simulation models maintain this structure over the simulation period. 


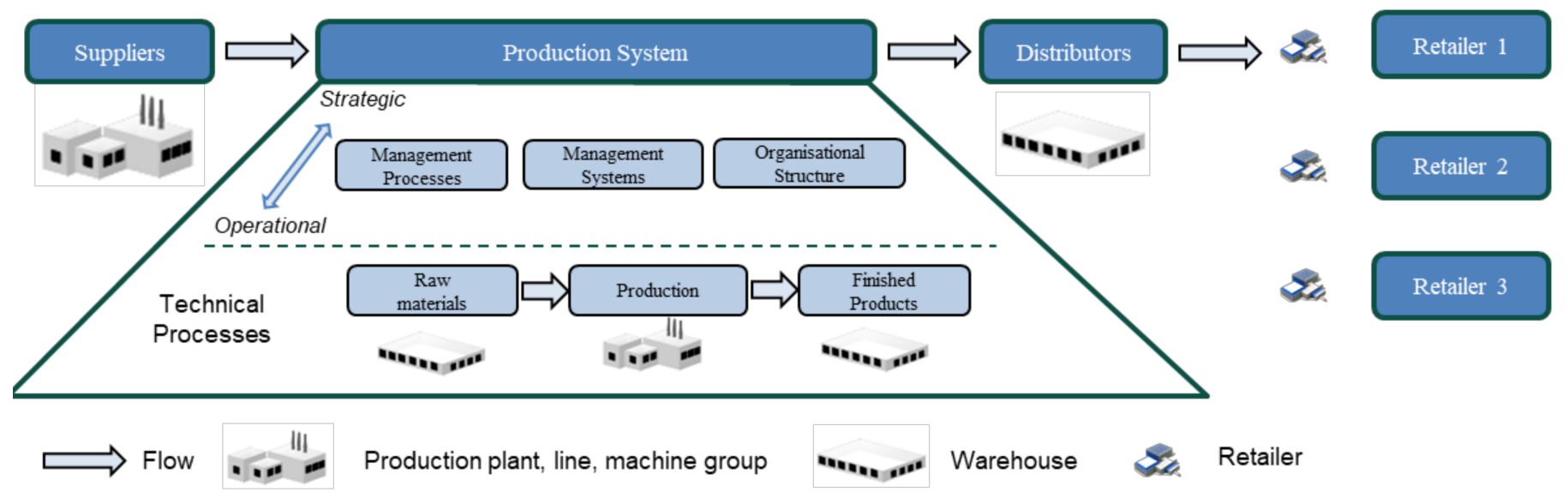

Figure 7. Structure of the simulation study (own elaboration).

\subsubsection{Key Performance Indicators}

The results are calculated from the simulation for all models to evaluate the response according to the following key performance indicators:

- Cumulated demand (\# thous. products);

- Cumulated production (\# thous. products): the cumulative sum of all car units produced over the 500 simulated production weeks;

- $\varnothing$ Availability of the production plant (\%);

- $\quad \varnothing$ Performance at the final production step (\# thous. products/week);

- $\varnothing$ Quality at the final production step with one-way and no loops (\%);

- $\quad \varnothing$ Capacity level (\# thous. products);

- Implementation time (time period);

- Labor productivity (products/employee $\times$ week);

- Cumulated stocks (\# mill. products);

- $\quad \varnothing$ Production lead time (\# weeks): the number of weeks between the placement of the order and the delivery of the product for its distribution;

- Cumulated service level (\%): the quantity of units delivered on time divided by the total number of delivered units;

- Profits (million euros): the result of the multiplication of the number of produced units by the margin that was provided for the type of produced car;

- Cumulated operational costs (million euros): consists of all costs related to the production system operations. It is the sum of procurement, production and distribution costs considering raw materials costs, transportation activities, working capital, labor costs, working shifts, and maintenance costs. The running costs of the project initiative are also included;

- Cumulated investment (million euros): the amount of the investment made to improve the production system. It can be due to the implementation of Industry 4.0 technologies;

- $\quad$ Return on investment (ROI) (million euros): the margin of the products that can be produced thanks to the Industry 4.0 related investment minus the investment value.

\subsubsection{Creation of a Generic Simulation Model}

After the problem has been defined, modelers must start generating assumptions as well as defining the standard values that define the models. These provide the basis for the model behavior and how the research question arose.

First, assumptions are defined to simplify the model with a focus on the simulation goal:

- Distribution of finished products as given;

- Procurement of raw material as given;

- Each order has a production unit; 
- $\quad$ Bill of materials are not considered.

The following assumptions were made related to the points to be fulfilled in order to conduct a comparison between the simulation models for a defined simulation demand scenario:

- The same demand using replication;

- Same number of employees with same initial distribution and same capacity to perform warehouse activities;

- $\quad$ Same production logic for all simulation models;

- The warehouses have no stock capacity limitations;

- There is no transport limitation between the different production stages;

- $\quad$ There are two products, one existing product is in a mature stage with stable demand and provides 10,000 euros/unit of margin. The new model is in the process of being launched and provides 20,000 euros/unit. These values were used to calculate profits. If there is loss in volume, it is assumed that the new model will have the loss in volume due to unknown future demand;

- The simulation model considers sales losses starting from a customer order lead time greater than 60 days;

- A product is a finished product after it leaves the production facility;

- Time restrictions: first, the modeler must define a time horizon and the units of time. It is easy to fulfill that step by asking to what extent the simulation should be considered. In the case of the study, it has been decided to simulate four working years to evaluate influences in the medium and long term.

The system dynamics model consists of five sub-models: the supply chain flow sub-model, the production planning sub-model, the maintenance sub-model, the decisionmaking sub-model and the evaluation of improvements initiatives sub-model.

\subsection{Design of the Simulation Models Based on Various Industry 4.0 Use Cases}

For the fourth industrial revolution the same examples are simulated. Each of them refers to one of the clusters of the GUVEI-Model starting from an initial situation.

- Initial situation: the model starts with a supply chain system that has delivery problems. Therefore, there is a capability need, i.e., the production system is not able to supply the needed demand to the market. Causes are unknown and could be multiple, such as low availability level of machines, lack of training of employees, long lead times for procurement of spare parts, lack of supplies on-time, etc.

- Cluster 1 simulation model: from the basis of the initial situation, the use case of the first cluster consists of the implementation of sensors for equipment monitoring. As a result, it is possible to know the bottleneck resources, as well as to incur less reaction times for maintenance activities, as breakdowns would be known in real time.

- Cluster 2 simulation model: this steps consists of the utilization of data provided from sensors about availability, performance and quality to adjust the production planning to develop into reliable planning that can enhance service levels to customer and capacity utilization levels thanks to better forecasting and capacity planning.

- Cluster 3 simulation model: later, with the help of virtual reality, the training and qualification of employees can improve significantly, and problems can be detected earlier. Therefore, this use case will enable a better-quality rate, and a reduction of production times leading, as a result, to higher capacities.

- Cluster 4 simulation model: it consists of the implementation of CPS with mobile devices as well as intelligent AGV (automated guided vehicles) that will improve the availability and reaction times for manufacturing spare parts, as well as for production supplies as agents are interconnected and without delays in communication and decisions.

- Cluster 5 simulation model: finally, the last step consists of applying additive manufacturing to reduce production lead times, procurement lead times for raw materials, 
as well as for spare parts, enabling improvement of the capacity level of the plant and the reaction times.

Table 1 shows a review of the described use cases classified according to the technology applied, and, as can be seen, the element of the global production system is improved:

Table 1. Use Cases Definition (own elaboration).

\begin{tabular}{|c|c|c|c|c|}
\hline \multirow[b]{2}{*}{ No. } & \multirow[b]{2}{*}{ Cluster } & \multicolumn{3}{|c|}{ Use Cases Definition } \\
\hline & & Use Case & Technology & $\begin{array}{c}\text { Standard Global Production } \\
\text { System Element }\end{array}$ \\
\hline 1 & Get Data & Equipment Monitoring & Sensors & $\begin{array}{l}\text { Quality management and } \\
\text { robust processes }\end{array}$ \\
\hline 2 & Use Information & Production Planning & Data Analytics & Logistics and production control \\
\hline 3 & Apply in Specific & $\begin{array}{l}\text { Training and Task } \\
\text { Optimization }\end{array}$ & Virtual Reality & $\begin{array}{l}\text { Work organization and } \\
\text { employee orientation }\end{array}$ \\
\hline 4 & Expand to Global & Autonomous AGVs & $\begin{array}{l}\text { CPS (T4) \& Adaptive } \\
\text { Robots (T9) }\end{array}$ & Logistics and production control \\
\hline 5 & Continuous Improvement & $\begin{array}{l}\text { Production, Maintenance } \\
\text { and Equipment }\end{array}$ & Additive Manufacturing & $\begin{array}{l}\text { Quality management and robust } \\
\text { processes, logistics and } \\
\text { production control, product and } \\
\text { process development }\end{array}$ \\
\hline
\end{tabular}

\subsection{Simulation Models Logic Formulation}

The logic applied by the use cases in the simulation model are described in Table 2:

Table 2. Logic Formulation for the Use Cases (own elaboration).

\begin{tabular}{|c|c|c|c|c|c|}
\hline \multirow[b]{2}{*}{ No. } & \multirow[b]{2}{*}{$\begin{array}{l}\text { Simulation } \\
\text { Models }\end{array}$} & \multicolumn{4}{|c|}{ Logic Formulation } \\
\hline & & Use Case & Description of Impacts & Impact on KPIs & $\begin{array}{l}\text { Implementation } \\
\text { Lead Time } \\
\text { (Weeks) }\end{array}$ \\
\hline 1 & Cluster 1 & Equipment Monitoring & Maintenance Improvement & Plant Availability & 12 \\
\hline 2 & Cluster 2 & Production Planning & $\begin{array}{l}\text { Capacity Utilization } \\
\text { Improvement, Reliable Planning }\end{array}$ & Service Level & 8 \\
\hline 3 & Cluster 3 & $\begin{array}{l}\text { Training and Task } \\
\text { Optimization }\end{array}$ & $\begin{array}{c}\text { Product and Process } \\
\text { Optimization, Quality } \\
\text { Improvement, Staff Qualification }\end{array}$ & $\begin{array}{l}\text { Plant Capacity, Lead } \\
\text { Times, Quality Rate }\end{array}$ & 24 \\
\hline 4 & Cluster 4 & Autonomous AGVs & Logistics Improvement & Logistics Availability & 12 \\
\hline 5 & Cluster 5 & $\begin{array}{l}\text { Production, Maintenance } \\
\text { and Equipment }\end{array}$ & $\begin{array}{l}\text { Global Supply Chain } \\
\text { Times Reduction }\end{array}$ & Lead Times & 18 \\
\hline
\end{tabular}

\section{Results}

The results for the low and high demand-scenarios are described in Table 3:

Table 3 shows how the results improved from the initial situation to the implementation of cluster 5, as they are cumulative implementation steps. From the development, availability rates change from almost $50 \%$ in the initial situation to more than $90 \%$ in cluster 5. Moreover, it is important to point out how production almost tripled the value of the initial situation and how the service level improved from $77 \%$ to more than $98 \%$.

The level of stocks reduces by more than seven times as the manufacturing system has the capability to supply most of market demand in cluster 5 , while in the initial situation the system has no capacity to meet demand. This occurs due to the increase of the performance rate of the supply chain processes as they almost double the output per time unit. In addition, the continuous increase of availability and quality rates from initial situation to 
cluster 5 contribute to this effect of increasing the capacity for meeting market demand. All of these improvements imply the decrease of customer order lead time from 183 to 82 days.

Table 3. Simulation results for the high-demand scenario.

\begin{tabular}{|c|c|c|c|c|c|c|c|}
\hline \multirow[b]{2}{*}{ No. } & \multirow[b]{2}{*}{ Key Indicator } & \multicolumn{6}{|c|}{ Simulation Models: Cumulative Improvements with the GUVEI-Model } \\
\hline & & $\begin{array}{c}\text { Initial } \\
\text { Situation }\end{array}$ & Cluster 1 & Cluster 2 & Cluster 3 & Cluster 4 & Cluster 5 \\
\hline 1 & $\sum$ Demand (\# $10^{3}$ products) & 363,195 & 363,195 & 363,195 & 363,195 & 363,195 & 363,195 \\
\hline 2 & $\sum$ Demand real (\#10 3 products) & 124,488 & 155,100 & 176,413 & 277,361 & 296,543 & 342,043 \\
\hline 3 & $\sum$ Production (\# products) & 105,719 & 130,778 & 148,564 & 237,511 & 256,324 & 307,680 \\
\hline 4 & $\varnothing$ Availability rate (\%) & 56.0 & 71.4 & 82.7 & 90.7 & 94.4 & 94.4 \\
\hline 5 & $\varnothing$ Performance rate $(\%)$ & 80.4 & 79.3 & 78.5 & 101.0 & 105.0 & 148.3 \\
\hline 6 & $\varnothing$ Quality rate $(\%)$ & 85.1 & 83.9 & 83.1 & 93.8 & 93.4 & 92.6 \\
\hline 7 & $\sum$ Stocks (\# $10^{6}$ products) & 42.4 & 35.8 & 31.1 & 10.8 & 6.4 & 6.8 \\
\hline 8 & Ø Capacity level (\# thous. products) & 210.1 & 260.3 & 296.0 & 474.6 & 512.4 & 845.5 \\
\hline 9 & Implementation time (weeks) & 0 & 12 & 20 & 44 & 56 & 74 \\
\hline 10 & $\begin{array}{l}\text { Labor productivity } \\
(\text { tons } / \text { empl. } \times \text { day) }\end{array}$ & 21.1 & 26.2 & 29.7 & 47.5 & 51.3 & 61.5 \\
\hline 11 & $\varnothing$ WIP stock (Mio. tons) & 0.7 & 0.8 & 0.9 & 1.3 & 1.3 & 1.6 \\
\hline 12 & $\varnothing$ Production lead time (\# weeks) & 183.1 & 178.6 & 181.0 & 130.3 & 123.3 & 82.3 \\
\hline 13 & Cumulated service level (\%) & 77.2 & 83.6 & 87.0 & 97.4 & 97.8 & 98.4 \\
\hline 14 & $\sum$ Sales (million euros) & 651 & 1263 & 1689 & 3708 & 4092 & 5002 \\
\hline 15 & $\sum$ Operational costs (million euros) & 2544 & 2369 & 2215 & 1868 & 1865 & 2227 \\
\hline 16 & $\sum$ Profits (million euros) & -1893 & -1106 & -526 & 1866 & 2226 & 2775 \\
\hline 17 & $\sum$ Investment (million euros) & 0 & 100 & 150 & 750 & 950 & 1250 \\
\hline 18 & Return on investment (ROI) (\%) & - & 5.3 & 6.1 & 4.3 & 3.8 & 3.3 \\
\hline
\end{tabular}

Furthermore, it can be observed how at the beginning the organization was not making any profits, with a loss of -1893 million euros and how in each step it improves continuously, being positive only after cluster 3 and later. Following this development, the contribution of the different clusters' implementation on service and economic goals can be analyzed. In this context, clusters 1 and 2 provide higher ROI than later steps, however these are not enough to make profits. Therefore, it is required to invest at least in cluster 3 with an investment value of 600 million euros to be above zero, although the cumulative ROI decreases but the net balance is 1866 . Finally, with all five clusters implemented, the ROI of all clusters is 3.3 and the profits achieved is 2775 million euros.

Table 4 shows how the results improved from the initial situation to the implementation of cluster 5, as they are cumulative implementation steps. From the development, the availability rates change from almost $50 \%$ in the initial situation to more than $90 \%$ in the cluster 5. Moreover, it is important to point out how production almost tripled the value of the initial situation and how the service level improved from $80 \%$ to more than $96 \%$. Furthermore, it can be observed how the indicators present the same trend as in the previous scenario.

Table 4. Simulation results for the low-demand scenario.

\begin{tabular}{|c|c|c|c|c|c|c|c|}
\hline \multirow[b]{2}{*}{ No. } & \multirow[b]{2}{*}{ Key Indicator } & \multicolumn{6}{|c|}{ Simulation Models: Cumulative Improvements with the GUVEI-Model } \\
\hline & & $\begin{array}{c}\text { Initial } \\
\text { Situation }\end{array}$ & Cluster 1 & Cluster 2 & Cluster 3 & Cluster 4 & Cluster 5 \\
\hline 1 & $\sum$ Demand (\# $10^{3}$ products) & 308,738 & 308,738 & 308,738 & 308,738 & 308,738 & 308,738 \\
\hline 2 & $\sum$ Demand real ( $\# 10^{3}$ products) & 124,488 & 155,100 & 176,413 & 277,361 & 296,543 & 312,043 \\
\hline 3 & $\sum$ Production (\# products) & 105,719 & 130,778 & 148,564 & 237,511 & 256,324 & 307,680 \\
\hline 4 & $\varnothing$ Availability rate (\%) & 56.0 & 71.4 & 82.7 & 90.7 & 94.4 & 94.4 \\
\hline 5 & $\varnothing$ Performance rate $(\%)$ & 80.4 & 79.3 & 78.5 & 101.0 & 105.0 & 148.3 \\
\hline 6 & $\varnothing$ Quality rate $(\%)$ & 85.1 & 83.9 & 83.1 & 93.8 & 93.4 & 92.6 \\
\hline 7 & $\sum$ Stocks (\# $10^{6}$ products $)$ & 42.4 & 35.8 & 31.1 & 10.8 & 6.4 & 6.8 \\
\hline 8 & Ø Capacity level (\# thous. products) & 210.1 & 260.3 & 296.0 & 474.6 & 512.4 & 845.5 \\
\hline
\end{tabular}


Table 4. Cont.

\begin{tabular}{|c|c|c|c|c|c|c|c|}
\hline \multirow[b]{2}{*}{ No. } & \multirow[b]{2}{*}{ Key Indicator } & \multicolumn{6}{|c|}{ Simulation Models: Cumulative Improvements with the GUVEI-Model } \\
\hline & & $\begin{array}{c}\text { Initial } \\
\text { Situation }\end{array}$ & Cluster 1 & Cluster 2 & Cluster 3 & Cluster 4 & Cluster 5 \\
\hline 9 & Implementation time (weeks) & 0 & 12 & 20 & 44 & 56 & 74 \\
\hline 10 & Labor productivity (tons/empl. $\times$ day) & 21.1 & 26.2 & 29.7 & 47.5 & 51.3 & 61.5 \\
\hline 11 & Ø WIP stock (Mio. tons) & 0.7 & 0.8 & 0.9 & 1.3 & 1.3 & 1.6 \\
\hline 12 & $\varnothing$ Production lead time (\# weeks) & 174.6 & 168.1 & 170.2 & 109.7 & 99.7 & 34.1 \\
\hline 13 & Cumulated service level (\%) & 79.6 & 85.6 & 87.2 & 95.8 & 96.2 & 96.8 \\
\hline 14 & $\sum$ Sales (million euros) & 1051 & 1647 & 2069 & 3957 & 4300 & 4802 \\
\hline 15 & $\sum$ Operational costs (million euros) & 2544 & 2369 & 2215 & 1868 & 1866 & 2231 \\
\hline 16 & $\sum$ Profits (million euros) & -1493 & -722 & -146 & 2089 & 2434 & 2571 \\
\hline 17 & $\sum \overline{\text { Investment (million euros) }}$ & 0 & 100 & 150 & 750 & 950 & 1250 \\
\hline 18 & Return on investment (ROI) (\%) & - & 5.2 & 6.0 & 4.1 & 3.6 & 2.9 \\
\hline
\end{tabular}

\section{Discussion}

The conceptual model for the integration of Industry 4.0 technologies with relevant improvement strategies supports managers in their decision-making processes when considering Industry 4.0 projects in relation to the improvement strategies. Managers should not limit their optimization strategies to new technologies, but should consider the other improvement strategies that are available. Furthermore, the optimization should not be done in an improper sequence as this would lead to inefficiency and non-successful project deployment. Therefore, by following the integration model, it would enable the discarding of cases, such as the development of a virtual process, e.g., a digital twin model of the manufacturing process and related production planning and control, when the process and the methods are not properly defined and controlled after the application of lean manufacturing and Six Sigma.

Moreover, the model results show substantial advantages for road-map development as the simulation model allows to quantify the effects of the various use cases and the conceptual model shows how in order to become virtual there are necessary steps, i.e., the obtaining and using of the data steps of the GUVEI-Model that act as enablers for the last three steps of the model. As a result, the main performance increase in the study occurs for the use cases when they become virtual, and based on this, the expansion and improvement of these cases. However, in order to be able to reach this great optimization in relevant indicators, monitoring and collecting all data related to the manufacturing organization is needed, as well as turning this data into usable information for analysis and interpretation. If the two first steps of the GUVEI-Model are not properly completed, the outcomes as virtual models would not be complete and, therefore, it would not lead to a significant improvement. As this challenge has been analyzed for decades, it is necessary to improve these two steps iteratively, i.e., monitoring and gathering data and treating these data in order to overcome the barrier of not reaching the expected results of new technologies.

Based on the research performed, Figure 8 depicts how improvement projects have to be defined in a way that is aligned with organizational goals and the areas influencing these targets. Therefore, the model and results developed in the paper show that managers need to declare clear goals, and have a good knowledge of their organizational capabilities and of the future functionalities that will be needed to reach their targets. For this purpose, managerial positions require processes of mapping for organizational, technical, and staffing factors, as well as a maturity model to monitor and develop their organizations. On this basis an assessment of current capabilities and their classification according to a maturity index model can be performed. Therefore, Figure 8 provides a framework for managers to apply and obtain the benefits of the conceptual and simulation models developed in this research. These first two steps would be to define the current status assessment of the manufacturing organization while also stating the goals. Later, based on the current maturity level for certain functions and the targets defined, the areas with 
gaps for reaching the target levels can be derived. With an identified gap and related strategic decision-making, a strategic program can be established. After this step, a topdown approach for the definition of improvement project initiatives can be initiated and validated for greenfield future factories. However, brownfield companies also have ongoing improvement and Industry 4.0 related projects. Therefore, in a certain rolling period, it is necessary to assess how these running projects contribute to organizational targets and if they should be stopped, changed, postponed, or if they should continue their established planning process. For this kind of decision-making, it is key to assess if the strategic roadmap and the on-going projects match the needs of the organization in order to reach the organizational capabilities that enable a company to achieve its goals. In this context, the optimization model developed provides a framework for the identification of weak areas, the determination of suitable steps for their improvement and an evaluation scheme for project initiation. Managers can develop a digital twin model for the continuous monitoring of organizational maturity levels, enabling the assisted identification of functional gaps and deviations, as well as the automated simulation of alternatives for improvement. In this context, an important step when considering the project decision-making, as well as its successful implementation, and latter sustainable application is the human factor role. Finally, resources constraints, i.e., staff, time, money, etc., should be considered when developing the improvement project's final roadmap.
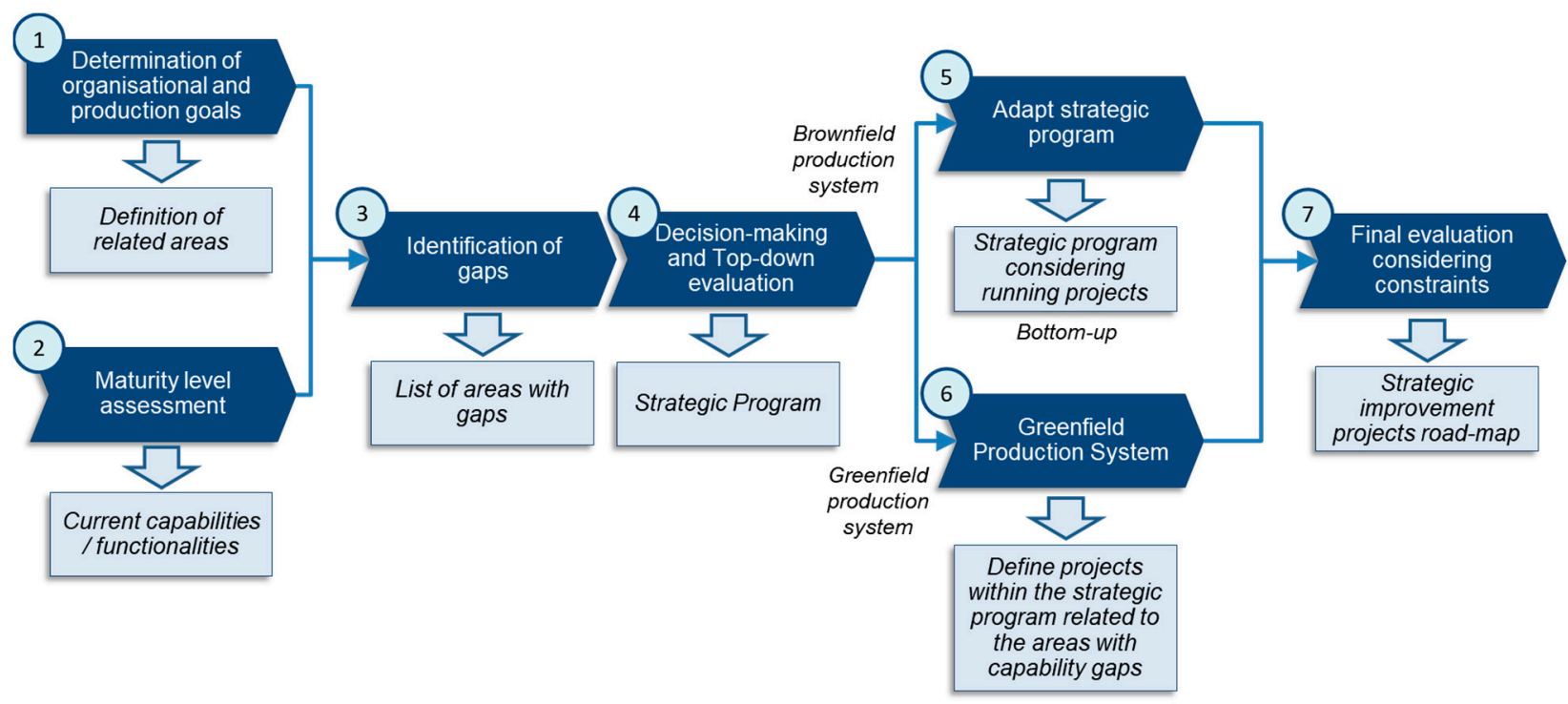

Figure 8. Digital twin manufacturing model for dynamic maturity level assessment and for simulating project improvement impacts (own elaboration).

\section{Conclusions}

Based on the research performed, it was concluded that there is a need to study the improvement techniques that exists before the fourth industrial revolution can be integrated with new technologies. As a result, the study provides managers with a model for monitoring the current state of the manufacturing organization, as well as for the identification and evaluation of optimization alternatives for the development of improvement roadmaps. Therefore, managers are provided with a framework to rethink their optimization strategies by orientating their decision-making on the organizational targets. However, before implementing an improvement, the area requiring an optimization should be first identified. For that purpose, a maturity level model is generated to be assessed by dynamically knowing in each moment the status of organizational functionalities or capabilities. Later, for knowing what to do for fulfilling the need discovered from the maturity model, relevant optimization alternatives from improvement strategies and Industry 4.0 were analyzed providing an overview of best-available strategies and technologies that can enhance the manufacturing system. On this basis, the integration model between improvement strategies and new 
technologies was designed. By developing the integration model, a five-step approach called "GUVEI"-Model was generated, describing the generic steps to be tackled to achieve a fully digitalized company in the fourth industrial revolution and serving as a framework model for sustainable and continuous improvement.

Finally, to prove the utility of the conceptual a model, a simulation model was developed for the five steps of the GUVEI-Model, providing dynamic assessments. The results of the use cases show how the five steps of the GUVEI-Model provide cumulative improvements in the main relevant indicators. For instance, for the high demand scenario, the manufacturing organization, after having implemented the five steps, is able to supply three times the demand with also three times the labor productivity of the initial situation. Moreover, stock levels reduced by seven times while service levels change from $77 \%$ to more than $98 \%$. All of this enabled an increase of almost ten times in sales leading the profit figure transformation from almost a loss of 2000 to a profit near to 3000 million euros with an aggregated ROI above all investments of the five steps of around 3\%. The main turning point in the performance and economic indicators occurred after the third step, i.e., becoming virtual, while the first two steps of obtaining and using data, acted as enablers. Therefore, in practice, the development of dynamic maturity assessment in a digital twin model can provide significant advantages for manufacturing companies as they can have assisted decision-making support and constant guidance of what to improve on based on predefined criteria, as well as how to measure the impacts as the use cases have shown.

Limitations and therefore, future research areas, are around how to apply this in real organizations, as well as how to develop the maturity model for different industries. As the current set-up is a generic approach, future research should focus on how to develop the model for specific use cases in particular industrial sectors and processes. Furthermore, there is a gap in the implementation of all levels, areas and factors in a digital twin model with simulation and artificial intelligence capabilities. In addition, the development of the automatic maturity assessment of each function within any manufacturing organization is a limitation and a potential future research area.

To summarize, the research work shows the potential benefits of the conceptual model for optimization. As a result, the proposed methodology provides a useful tool for organizations and managers to sustainably develop roadmaps based on improvement strategies and new technologies.

Author Contributions: Conceptualization, S.G.-G.; Methodology, S.G.-G., M.G. and J.H.; Software and programming, S.G.-G.; Validation, S.G.-G.; Data Analysis, S.G.-G.; Writing and Review and Editing, M.G., S.G.-G. All authors have read and agreed to the published version of the manuscript.

Funding: This research received no external funding.

Institutional Review Board Statement: Not applicable.

Informed Consent Statement: Not applicable.

Conflicts of Interest: The authors declare no conflict of interest.

\section{References}

1. Zaidin, N.H.M.; Diah, M.N.M.; Yee, P.H.; Sorooshian, S. Quality management in industry 4.0 era. J. Manag. Sci. $2018,8,82-91$. [CrossRef]

2. Klingenberg, C.; Antunes, J. Industry 4.0: What makes it a revolution. EurOMA 2017, 2017, 1-11.

3. Tortorella, G.L.; Fogliatto, F.S.; Cauchick-Miguel, P.A.; Kurnia, S.; Jurburg, D. Integration of Industry 4.0 technologies into Total Productive Maintenance practices. Int. J. Prod. Econ. 2021, 240, 108224. [CrossRef]

4. Frank, A.G.; Dalenogare, L.S.; Ayala, N.F. Industry 4.0 technologies: Implementation patterns in manufacturing companies. Int. J. Prod. Econ. 2019, 210, 15-26. [CrossRef]

5. Garza-Reyes, J.A.; Lim, M.K.; Zisis, S.; Kumar, V.; Rocha-Lona, L. Adoption of operations improvement methods in the Greek engineering sector. In Proceedings of the 2015 International Conference on Industrial Engineering and Operations Management (IEOM), Dubai, United Arab Emirates, 3-5 March 2015; pp. 1-8.

6. Sanders, A.; Elangeswaran, C.; Wulfsberg, J.P. Industry 4.0 implies lean manufacturing: Research activities in industry 4.0 function as enablers for lean manufacturing. J. Ind. Eng. Manag. (JIEM) 2016, 9, 811-833. [CrossRef] 
7. Sony, M. Industry 4.0 and lean management: A proposed integration model and research propositions. Prod. Manuf. Res. 2018, 6, 416-432. [CrossRef]

8. Kolberg, D.; Zühlke, D. Lean automation enabled by industry 4.0 technologies. IFAC-PapersOnLine 2015, 48, 1870-1875. [CrossRef]

9. Dubey, R.; Gunasekaran, A. Agile manufacturing: Framework and its empirical validation. Int. J. Adv. Manuf. Technol. 2015, 76, 2147-2157. [CrossRef]

10. Qin, J.; Liu, Y.; Grosvenor, R. A categorical framework of manufacturing for industry 4.0 and beyond. Procedia CIRP 2016, 52, 173-178. [CrossRef]

11. Mortensen, S.T.; Nygaard, K.K.; Madsen, O. Outline of an industry 4.0 awareness game. Procedia Manuf. 2019, 31, 309-315. [CrossRef]

12. Fatorachian, H.; Kazemi, H. A critical investigation of Industry 4.0 in manufacturing: Theoretical operationalisation framework. Prod. Plan. Control. 2018, 29, 633-644. [CrossRef]

13. Nascimento, D.L.M.; Alencastro, V.; Quelhas, O.L.G.; Caiado, R.G.G.; Garza-Reyes, J.A.; Rocha-Lona, L.; Tortorella, G. Exploring Industry 4.0 technologies to enable circular economy practices in a manufacturing context: A business model pro-posal. J. Manuf. Technol. Manag. 2019, 30, 607-627. [CrossRef]

14. Chiarello, F.; Trivelli, L.; Bonaccorsi, A.; Fantoni, G. Extracting and mapping industry 4.0 technologies using wikipedia. Comput. Ind. 2018, 100, 244-257. [CrossRef]

15. Dalmarco, G.; Ramalho, F.R.; Barros, A.C.; Soares, A.L. Providing industry 4.0 technologies: The case of a production technology cluster. J. High Technol. Manag. Res. 2019, 30, 100355. [CrossRef]

16. Gökalp, E.; Şener, U.; Eren, P.E. Development of an assessment model for industry 4.0: Industry 4.0-MM. In Proceedings of the International Conference on Software Process Improvement and Capability Determination, Palma de Mallorca, Spain, 4-5 October 2017; Springer: Cham, Switzerland, 2017; pp. 128-142.

17. Rübel, S.; Emrich, A.; Klein, S.; Loos, P. A maturity model for business model management in industry 4.0. In Multikonferenz Wirtschaftsinformatik; Leuphana Universität Lüneburg, Institut für Wirtschaftsinformatik: Lüneburg, Germany, 2018 ; pp. 6-9.

18. Lu, H.P.; Weng, C.I. Smart manufacturing technology, market maturity analysis and technology roadmap in the computer and electronic product manufacturing industry. Technol. Forecast. Soc. Change 2018, 133, 85-94. [CrossRef]

19. Zeller, V.; Hocken, C.; Stich, V. Acatech Industrie 4.0 maturity index-a multidimensional maturity model. In Proceedings of the IFIP International Conference on Advances in Production Management Systems, Seoul, Korea, 26-30 August 2018; pp. 105-113.

20. Lee, J.; Bagheri, B.; Kao, H.A. A cyber-physical systems architecture for industry 4.0-based manufacturing systems. Manuf. Lett. 2015, 3, 18-23. [CrossRef]

21. Dalenogare, L.S.; Benitez, G.B.; Ayala, N.F.; Frank, A.G. The expected contribution of Industry 4.0 technologies for industrial performance. Int. J. Prod. Econ. 2018, 204, 383-394. [CrossRef]

22. Porter, M.E. Creating and sustaining superior performance. In Competitive Advantage; The Free Press: New York, NY, USA, 1985; pp. 167-206.

23. Schuh, G.; Anderl, R.; Gausemeier, J.; ten Hompel, M.; Wahlster, W. (Eds.) Industrie 4.0 Maturity Index: Managing the Digital Transformation of Companies; Herbert Utz Verlag GmbH: München, Germany, 2017.

24. Lodgaard, E.; Dransfeld, S. Organizational aspects for successful integration of human-machine interaction in the industry 4.0 era. Procedia CIRP 2020, 88, 218-222. [CrossRef]

25. Issa, A.; Hatiboglu, B.; Bildstein, A.; Bauernhansl, T. Industrie 4.0 roadmap: Framework for digital transformation based on the concepts of capability maturity and alignment. Procedia CIRP 2018, 72, 973-978. [CrossRef]

26. Smętkowska, M.; Mrugalska, B. Using Six Sigma DMAIC to improve the quality of the production process: A case study. Procedia-Soc. Behav. Sci. 2018, 238, 590-596. [CrossRef]

27. Alcalá Gámez, A.; Cadena Badilla, M. Situando el SMED como una Herramienta de “Lean Manufacturing” para Mejorar los Tiempos de Preparación, Ajuste y Cambios de Herramientas. 2009. Available online: http:/ / repositorioinstitucional.unison.mx/ handle/20.500.12984/1507 (accessed on 9 November 2021).

28. Godinho Filho, M. Complementing lean with quick response manufacturing: Case studies. Int. J. Adv. Manuf. Technol. 2017, 90, 1897-1910.

29. Gupta, V.; Jain, R.; Meena, M.L.; Dangayach, G.S. Six-sigma application in tire-manufacturing company: A case study. J. Ind. Eng. Int. 2018, 14, 511-520. [CrossRef]

30. Stump, B.; Badurdeen, F. Integrating lean and other strategies for mass customization manufacturing: A case study. J. Intell. Manuf. 2012, 23, 109-124. [CrossRef]

31. Groten, M.; Gallego-García, S. A Systematic Improvement Model to Optimize Production Systems within Industry 4.0 Environments: A Simulation Case Study. Appl. Sci. 2021, 11, 11112. [CrossRef]

32. Chiarini, A.; Belvedere, V.; Grando, A. Industry 4.0 strategies and technological developments. An exploratory research from Italian manufacturing companies. Prod. Plan. Control. 2020, 31, 1385-1398. [CrossRef]

33. Gottge, S.; Menzel, T.; Forslund, H. Industry 4.0 technologies in the purchasing process. Ind. Manag. Data Syst. 2020, 120, 730-748. [CrossRef]

34. Crnjac, M.; Veža, I.; Banduka, N. From concept to the introduction of industry 4.0. Int. J. Ind. Eng. Manag. 2017, 8, 21-30.

35. Ustundag, A.; Cevikcan, E. Industry 4.0: Managing the Digital Transformation; Springer: Cham, Switzerland, 2017. 
36. García, S.G.; García, M.G. Industry 4.0 implications in production and maintenance management: An overview. Procedia Manuf. 2019, 41, 415-422. [CrossRef]

37. Angerhofer, B.J.; Angelides, M.C. System dynamics modelling in supply chain management: Research review. In Proceedings of the 32nd Conference on Winter Simulation, Society for Computer Simulation International, Orlando, FL, USA, 10-13 December 2000; pp. 342-351.

38. Sterman, J.D. Business Dynamics: Systems Thinking and Modeling for a Complex World; Irwin/McGraw-Hill: New York, NY, USA, 2000.

39. Campuzano, F.; Bru, J.M. Supply Chain Simulation: A System Dynamics Approach for Improving Performance; Springer Science \& Business Media: Berlin/Heidelberg, Germany, 2011. 